\title{
THE IMPACTS OF TYPICAL DROUGHT EVENTS ON TERRESTRIAL VEGETATION IN CHINA
}

\author{
Jianhua Yang ${ }^{1}$, Jianjun $\mathrm{Wu}^{1}$, Hongkui Zhou ${ }^{1}$, Xinyi $\operatorname{Han}^{1}$ \\ ${ }^{1}$ Beijing Normal University, Faculty of Geographical Science, China - yangjh15@mail.bnu.edu.cn
}

Commission ICWG III/Iva

KEY WORDS: vegetation type, drought event, SPEI, the North China, the Southwest China

\begin{abstract}
:
In our study, according to the statistical results of standardized precipitation evapotranspiration index (SPEI), we chose two drought events which occurred in the North China during 2001 and in the Southwest China from 2009 to 2010. And two of the Global Land Surface Satellite (GLASS) products had been used to evaluate the impacts of drought on vegetation, including the leaf area index (LAI) and the fraction of absorbed photosynthetically active radiation (FAPAR). The results show that: (1) In the development process of a drought event, the anomaly of remote sensing parameters (LAI and FAPAR) usually falls firstly and then rises as the drought changes from moderate to severe and then to moderate. This indicates that the effects of drought on vegetation remote sensing parameters are closely related to the severity of drought disaster. (2) The response of different vegetation types to the drought disaster is different. Compared with the forests, the response of grasslands to drought disaster is earlier. For example, the duration affected by drought disaster in grassland is longer 1/3 than the forests in the Southwest China. (3) Irrigation is an effective measure to mitigate the effects of drought. Irrigated croplands are less affected by drought than non-irrigated croplands and grasslands. In the North China, the decrease amplitude of irrigated croplands' remote sensing parameters is about half of non-irrigated croplands'.
\end{abstract}

\section{INTRODUCTION}

In recent decades, with the effects of global climate change and human activities, the drought condition has become more serious. A lot of study has been carried out on the relationship between the drought indexes (such as PDSI, SPI and SPEI) and the vegetation remote sensing parameters. However, there are not enough study about how one specific drought event affect the different vegetation types, and the NDVI is the mainly remote sensing parameters which was chosen by the past research. The main objective of this study was to explore the different responses of different vegetation in one typical drought event based on the LAI, FAPAR, land cover data and SPEI.

\section{MATERIALS AND METHODS}

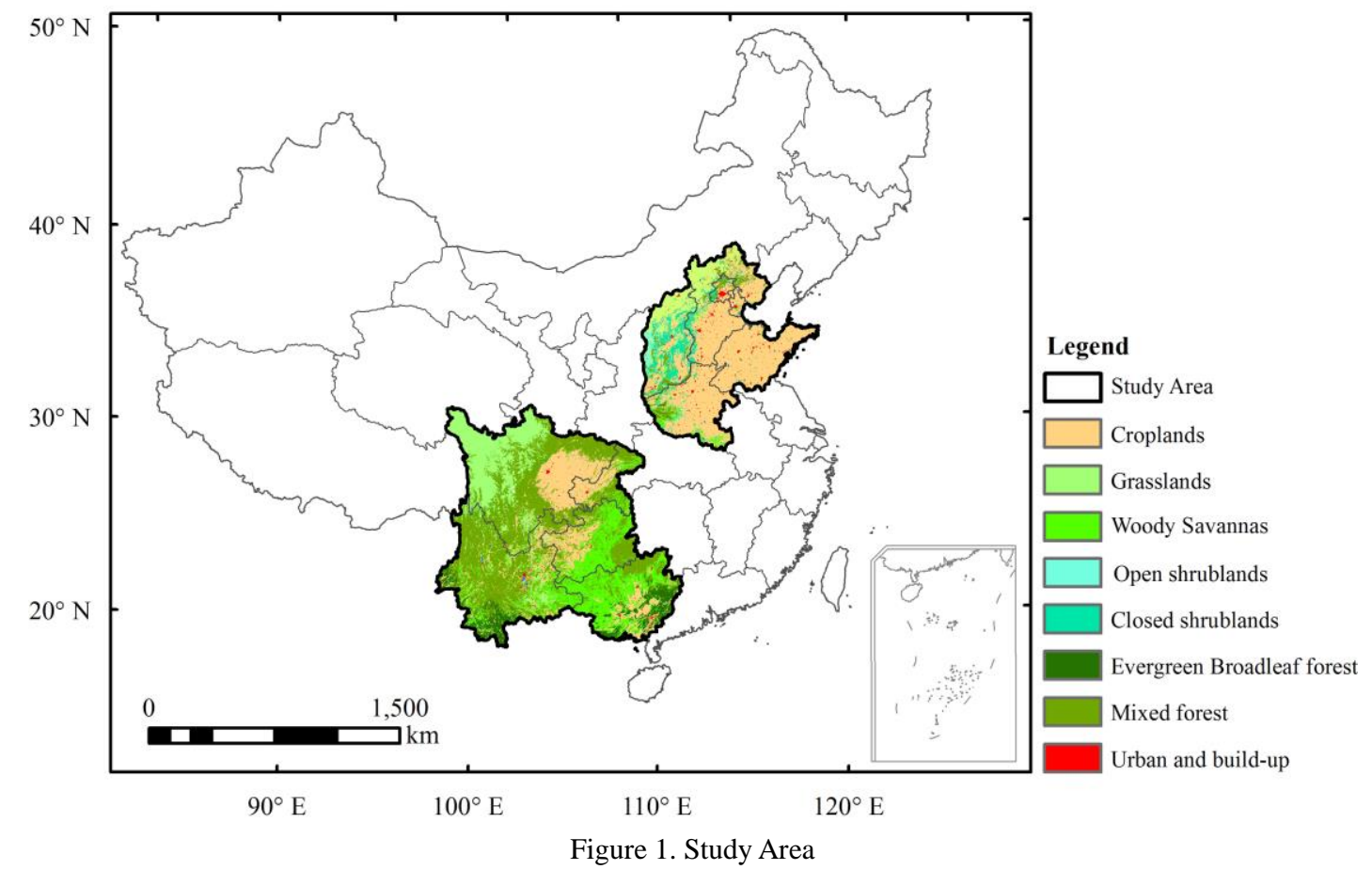


The North China and the Southwest China were chosen as the study area (Figure 1). Croplands are the main land cover of the North China, and drought has great influences on crop production of this region, especially in the north no-irrigated areas of the region. In the North China, we chose the drought event occurred from April to November in 2001.

The climate types are primarily subtropical monsoon, lowlatitude climate, and mountain climate in the Southwest China. The special climatic conditions cause a diversity of natural geographic characteristics and vegetation types. The Southwest China experienced a serious drought from 2009 to 2010 that affected extensive regions from Yunnan, Guangxi to Sichuan, Guizhou and Chongqing (Jing Yang, 2012), thus the typical drought event was chosen in this region.

\subsection{Data}

In order to analysis the different response of different vegetation on the drought, two of the Global Land Surface Satellite (GLASS) products (LAI and FAPAR) and the first layer of MODIS Land Cover Data in MCD12Q1(Mark A. Friedl et al., 2010a) was used as well. The SPEI which are produced by the Spanish National Research Council (CSIC, http://spei.csic.es/index.html) had been used to reveal the relationship between the change of vegetation and different level drought.

\subsection{Methods}

2.3.1 Diversion of Drought Degree: The SPEI was proposed firstly as an improved drought index of SPI (Vicente-Serrano et al., 2013a). Because not only the precipitation but also the reference evapotranspiration has been considered when calculated the SPEI, it is more suitable for studying the drought condition under the global warming. The computation of SPEI was performed according to Vicente-Serrano et al. (2010). The SPEI time scale of this study was set to 3 months. Table 1 presents the categorization of the dryness grade according to SPEI.

\begin{tabular}{cc}
\hline Categories & SPEI values \\
\hline No Drought & SPEI $>-0.5$ \\
Mild Drought & $-1.0<$ SPEI $\leq-0.5$ \\
Moderate Drought & $-1.5<$ SPEI $\leq-1.0$ \\
Severe Drought & $-2.0<$ SPEI $\leq-1.5$ \\
Extreme Drought & SPEI $\leq-2$ \\
\hline
\end{tabular}

Table 1. Categorization of drought grade by the SPEI (McKee et al., 1993; Paulo et al., 2012)

2.3.2 Analysis of Severity of Time Series SPEI Using Runs Theory: The runs theory which was proposed by Yevjevich has been widely used in drought characteristics analysis (Yevjevich, 1967). With the help of Figure2, we can understand the theory easily, the run is defined as a portion of time series of a drought index, in which all values are either above or below one selected truncation level, it is also called either a negative or positive run (AK Mishra et al., 2010).

The drought duration is expressed in a time period, during which a drought parameter is continuously below the critical level. Drought severity indicates a cumulative deficiency of a drought parameter below the critical level. Drought intensity is the average value of a drought parameter below the threshold level, which is measured as the drought severity divided by the duration. In this study, we got the drought duration of each drought event using the runs theory.

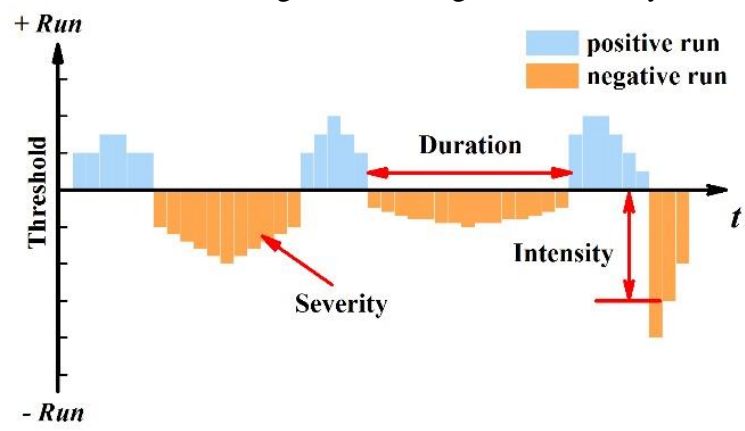

Figure 2. Run Theory Diagram

2.3.3 Analysis of the LAI and FAPAR: In order to analysis how the drought events affect different vegetation, we calculated the LAI anomalies and FAPAR anomalies by formula (1) and formula (2).

$$
\begin{gathered}
\overline{V I}=\sum_{i=1}^{n} V I_{i} / n \\
V I A N_{i}=V I_{i}-\overline{V I}
\end{gathered}
$$

where $\mathrm{VI}=\mathrm{LAI}$ or FAPAR

VIAN = LAI anomalies or FAPAR anomalies Since one drought event usually lasts for some time and it has continuous impacts on vegetation, the accumulations of LAI anomalies and FAPAR anomalies are calculated as a indicator of the cumulative effects of drought events on terrestrial vegetation as follows:

$$
\text { VIAN_Accumulation }=\sum_{i=t_{1}}^{i=t_{2}} \operatorname{VIAN}_{i}
$$

\section{RESULTS AND DISCUSSIONS}

\subsection{Different Influence of Drought Events on Different Vegetation Types}

It can be seen that the LAI anomalies and FAPAR anomalies during the drought periods were almost below the average values of them at no drought conditions (Figure3, Figure4). The decrease degree of the two vegetation remote sensing parameters showed an increase trend with the drought degree changed from mild to severe in the North China. The above phenomenon shows that drought usually have a negative influence on vegetation.

The influences of drought on different vegetation during the drought periods were different. It could be found that the grasslands were easily affected by the drought disasters compared with the mixed forests and closed shrublands. In the North China, the LAI anomalies and FAPAR anomalies at grasslands are significantly lower than those in closed shrublands at July in 2001. And in the Southwest China, the response of LAI and FAPAR to the drought disasters were earlier about 3 months than those in the mixed forest. 

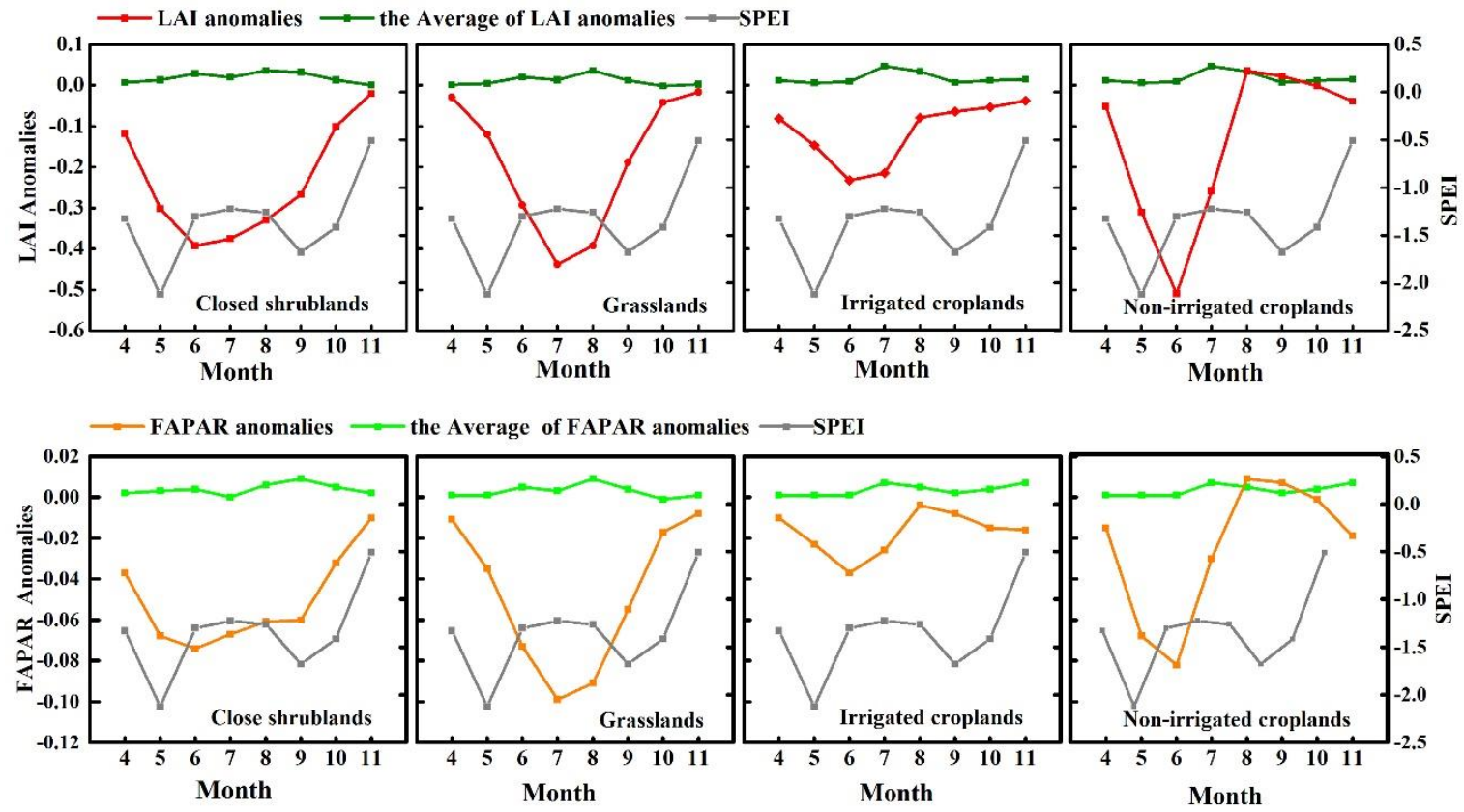

Figure 3. Drought effects on LAI and FAPAR of different vegetation in the North China
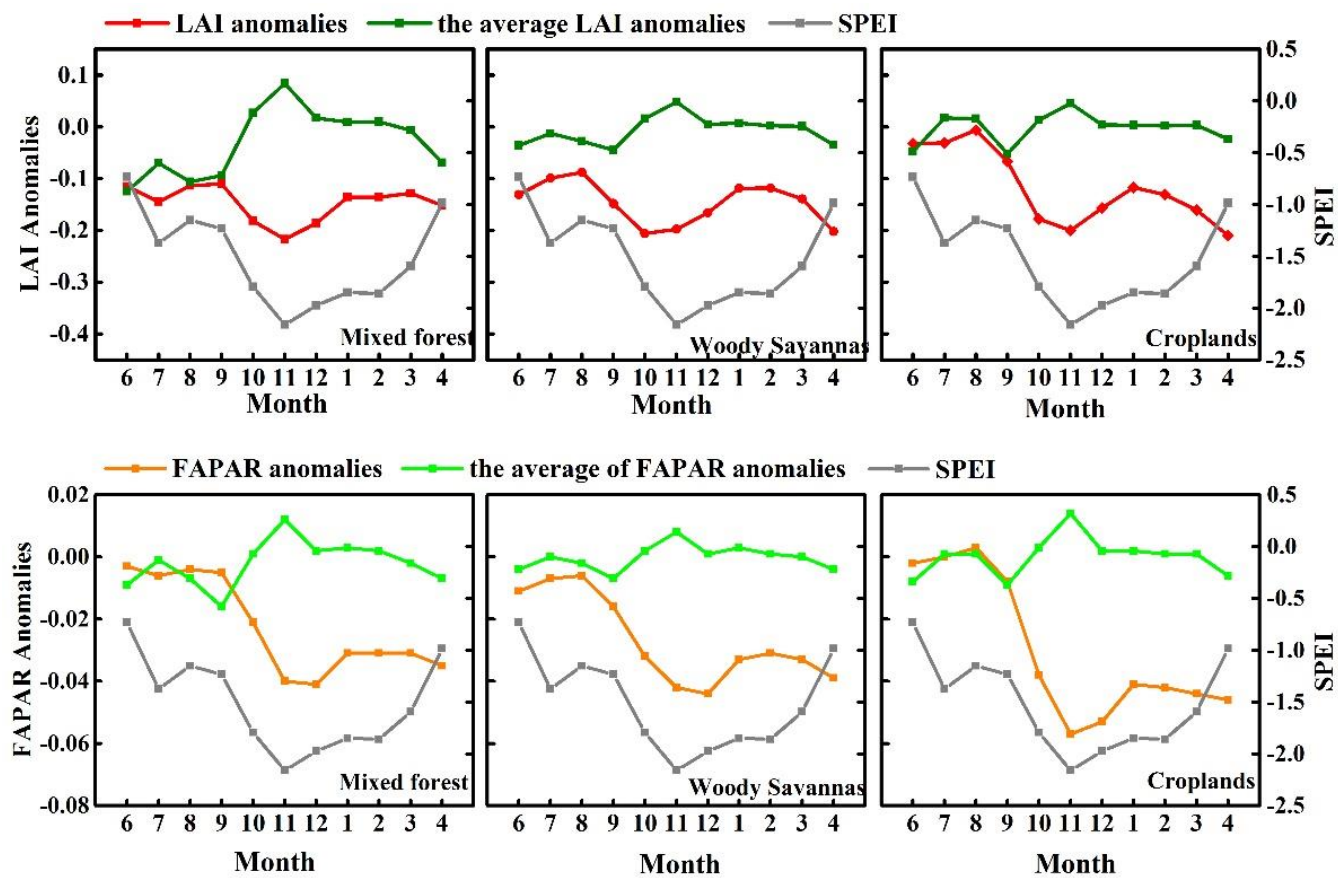

Figure 4. Drought effects on LAI and FAPAR of different vegetation in the Southwest China

Farmland irrigation is an effective measure to mitigate the effects of drought on crops. Irrigated farmland was less affected by the drought disasters than non-irrigated farmland, grassland and even the closed shrublands (Figure3). In the North China, the decrease amplitude of irrigated croplands' remote sensing parameters is about half of the non-irrigated croplands'. In June which severe drought occurred, the LAI of non-irrigated croplands decreased by 0.51 , while the LAI of irrigated croplands decreased by only 0.23 ; the FAPAR of nonirrigated farmland decreased by about 0.08 , while irrigated farmland only decreased by about 0.04 .

\subsection{Accumulative Effects Analysis of Drought on}

\section{Different Vegetation}

The accumulations of LAI and FAPAR during the drought periods could reflect the cumulative effect of drought disasters on different vegetation. Drought Severity is usually used to describe the cumulative deficiency of one drought parameter below the critical level (Figure 5, Figure 6). So it was able to help us understand the overall characteristics that different vegetation types influenced by the drought disaster by comparing with the spatial distributions of drought severity, the accumulations of vegetation remote sensing parameters at different land cover. 
We could find that the grasslands and shrublands in the North China suffered from severe drought. There was not enough water supplement when drought occurred in above regions, thus the accumulations of LAI anomalies and FAPAR anomalies at grasslands and shrublands were obviously lower than those in other regions (Figure5). From Figure 6, we can found that woody savannas were affected severely when severe drought disasters took place in the Southwest China from 2009 to 2010. This was because drought severity in
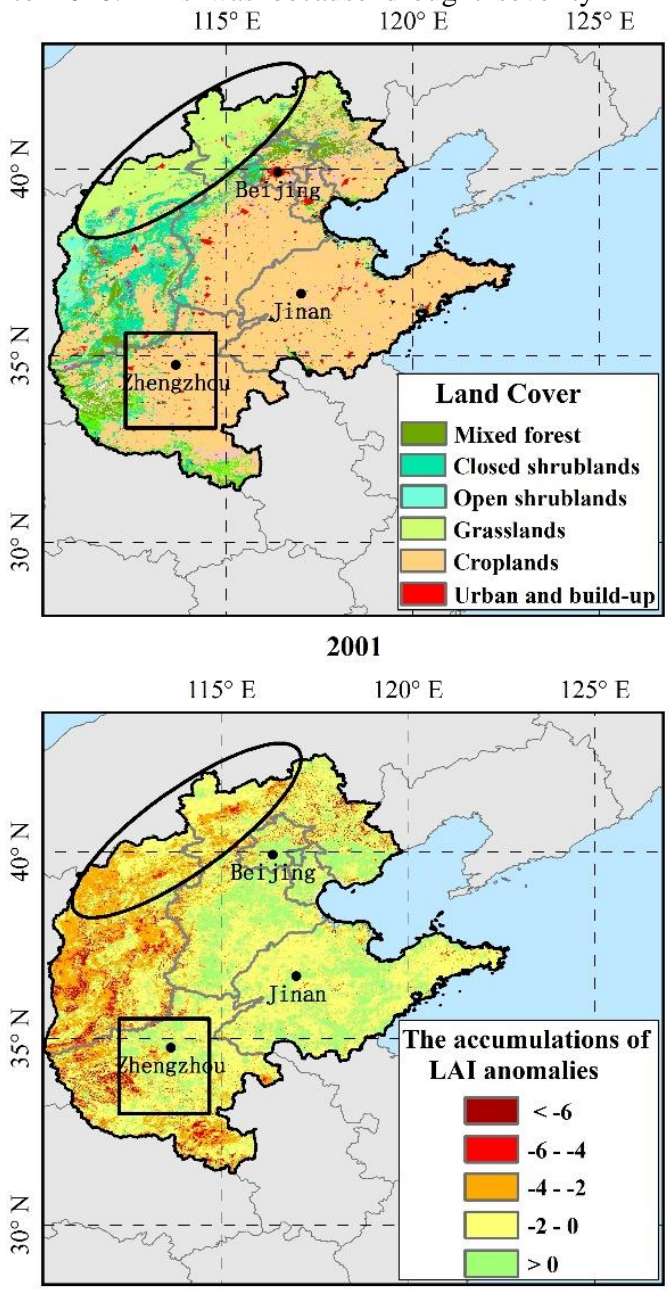

2001/04 2001/11 woody savannas was higher than other regions, and drought resistance of woody savannas was weaker than other vegetation. As for the croplands, it showed lower LAI and FAPAR anomalies compared with other regions experiencing similar drought condition, this because most croplands in Sichuan Basin belonged to no-irrigated croplands.

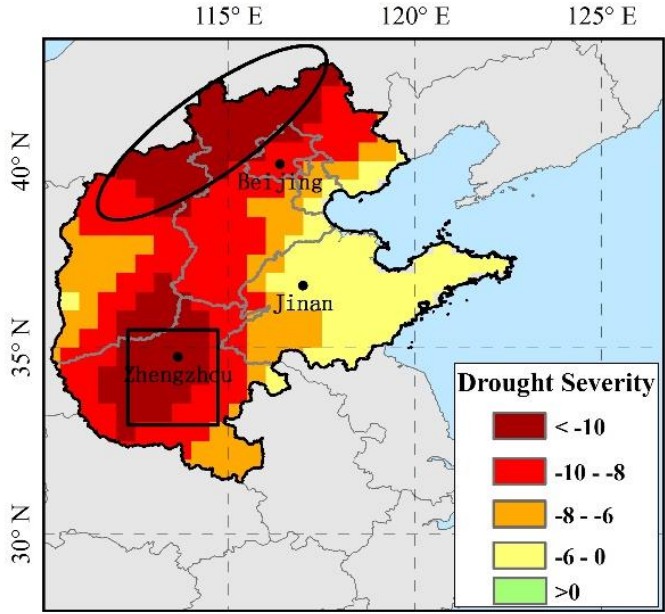

2001/04 2001/11

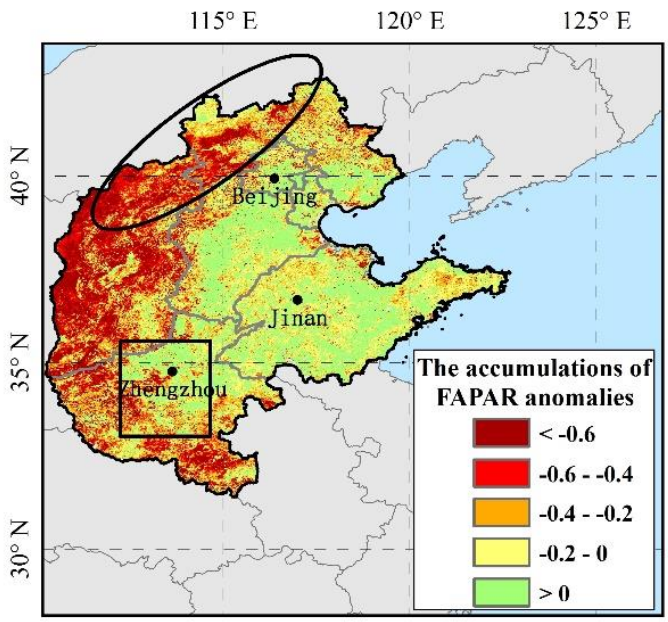

2001/04 2001/11

Figure 5. Spatial distribution of vegetation type, drought severity, and the accumulations of LAI and FAPAR anomalies in the North China 


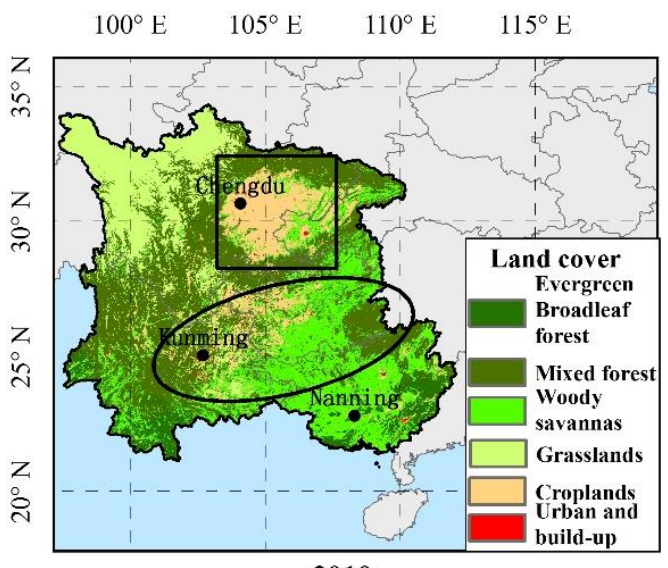

2010

$100^{\circ} \mathrm{E} \quad 105^{\circ} \mathrm{E} \quad 110^{\circ} \mathrm{E} \quad 115^{\circ} \mathrm{E}$

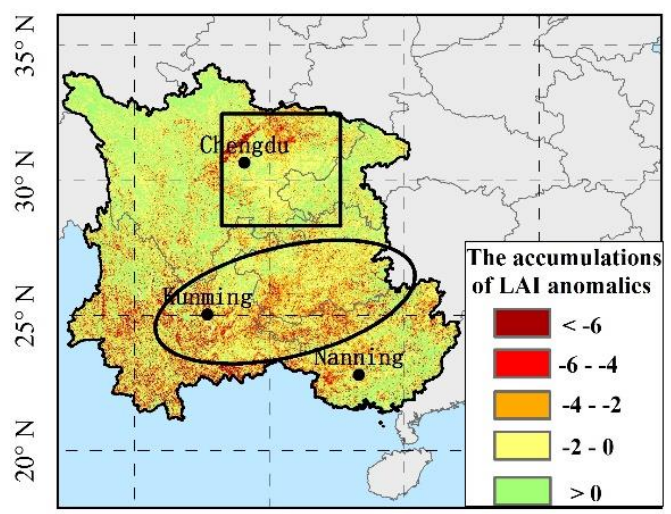

2009/6 2010/4 $100^{\circ} \mathrm{E} \quad 105^{\circ} \mathrm{E} \quad 110^{\circ} \mathrm{E} \quad 115^{\circ} \mathrm{E}$

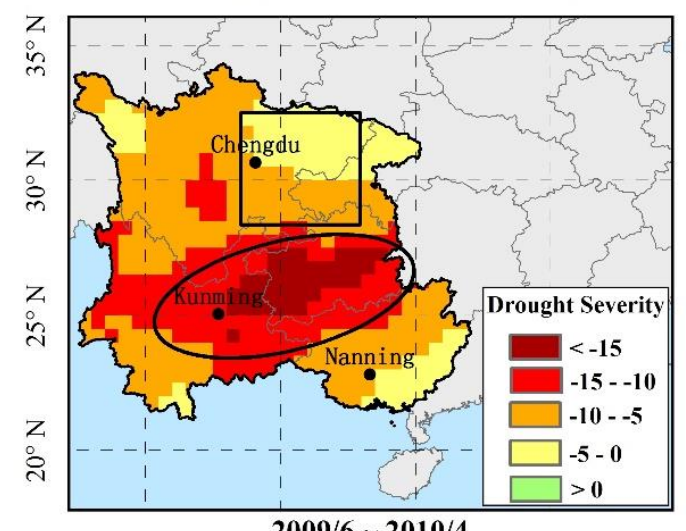

$2009 / 6 \sim 2010 / 4$

$100^{\circ} \mathrm{E} \quad 105^{\circ} \mathrm{E} \quad 110^{\circ} \mathrm{E} \quad 115^{\circ} \mathrm{E}$

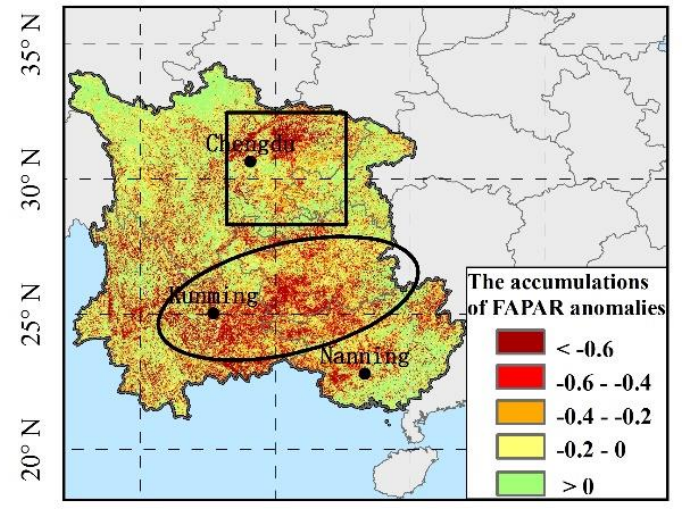

$2009 / 6 \sim 2010 / 4$

Figure 6. Spatial distribution of vegetation type, drought severity, and the accumulations of LAI and FAPAR anomalies in the Southwest China

\section{CONLUSIONS}

In this study, two typical drought events occurred in the North China and in the Southwest China were chosen based on SPEI. Through studying the different responses of different vegetation to the drought event, we can found that: The effects of drought on vegetation remote sensing parameters are closely related to the severity of drought disaster. The response of different vegetation to the drought is different, grasslands is easier to be influenced by the drought disasters compared with the forests. Irrigation can reduce the negative influences of drought on crops, irrigated croplands are less affected by drought than non-irrigated croplands, grasslands and even the closed shrublands.

\section{REFERENCES}

Mishra A K, Singh V P. A review of drought concepts[J]. Journal of Hydrology, 2010, 391(1):202-216.

Friedl M A, Sullamenashe D, Tan B, et al. MODIS Collection 5 global land cover: algorithm refinements and characterization of new datasets.[J]. Remote Sensing of Environment, 2010, 114(1):168-182.

Paulo A A, Rosa R D, Pereira L S. Climate trends and behaviour of drought indices based on precipitation and evapotranspiration in Portugal[J]. Natural Hazards \& Earth System Sciences, 2012, 12(5):1481-1491.
T.B. McKee, N.J. Doesken, J. Kleist. The Relationship of Drought Frequency and Duration to Time Scales Proceedings of the 8th Conference on Applied Climatology vol. 17, American Meteorological Society, Boston, MA (1993), pp. 179-183

Yevjevich, V. An Objective Approach to Definitions and Investigations of Continental Hydrologic Drought; Hydrology Paper No. 23; Colorado State University: Fort Collins, CO, USA, 1967.

Yang J, Gong D, Wang W, et al. Extreme drought event of 2009/2010 over southwestern China[J]. Meteorology \& Atmospheric Physics, 2012, 115(3-4):173-184. 